\title{
Numerical multiphysics modelling for the assessment of thermo-physical and energy performance of an advanced semi-opaque active façade
}

\author{
Balocco Carla*, Petrone Giuseppe \\ Department of Industrial Engineering, University of Firenze, Via Santa Marta 3, Firenze I-50139, \\ Italy
}

Email: carla.balocco@unifi.it

\begin{abstract}
The aim of this paper is to study an advanced semi-opaque active façade using a multi-physics modelling approach. The studied façade is to be understood as an integrated energy system as designed with innovative materials and system solutions. It is an envelope building component composed of opaque modules combined with transparent ones, in which multilayer panels are integrated, consisting of nano-structured materials and new-generation photovoltaic systems. The multi-physics approach used for simulations allowed consideration of fluid-dynamics and thermal behaviour of the components, including the phase change material (PCM) occurring in one of the system elements under external microclimatic stress, modifying its heat capacity over time. Numerical modelling based on RANS-turbulence models was implemented to simulate the multi-layer components. In particular, numerical solutions of buoyancy / forced driven flows and temperature fields were developed by means of an energy equation, taking into account the enthalpy variation in the solid/liquid computational domain connected with the phase change process. Simulation results show the airflow and thermal map computed in a chosen constraint configuration of the integrated system façade.
\end{abstract}

Keywords: Advanced Active Facade, CFD, Multiphysics, Energy Design, Sustainability.

\section{INTRODUCTION}

Recent research has proposed different classifications for the study of advanced building façade systems, in order to assess their thermal behaviour by transient simulations and experimental measurements $[1,2,3]$. The common basis of all this extensive research is the concept that a building envelope has to be conceived as a "self-sufficient building skin". This means that it behaves dynamically, incorporating different technologies (e.g. ventilation systems, decentralized heating/cooling units, heat exchangers, energy supply devices, energy storage, thermal buffering, sun shading purposes, lighting equipment, shading devices, and natural and/or forced ventilation in the cavities). The façade system is then developed as an advanced integrated modular building component (Multifunctional Facade Module - MFM), which can reduce energy consumption, summer cooling loads, winter heat losses. If designed ad hoc, the MFMs can also guarantee thermal comfort, natural lighting, acoustic insulation, correct building ventilation and indoor air quality [2]. Thermal performance of these special building envelopes has been investigated experimentally and numerically especially for the Mediterranean climate $[4,5]$.

Most of the literature has directed these advance multifunctional façade systems towards renewable energy source integration, passive and active solar applications and building plant system use connections, by means of experimental testing and/or validation and simulation $[6,7,8]$.

Although the experimental approach can provide accurate results, it is very time consuming, expensive and requires complex measuring systems with specific sensors, as well as being particularly design-dependent and not always easily reproducible. There are many numerical studies concerning the efficacy of PCMs used also in industrial applications and storage unit of thermal solar plants. In particular, in $[9,10]$ transient simulations on Latent Thermal Energy Storage systems (LHTESS), with the use of the nano-PCMs and metal foam for thermal storage applications, have been performed and results widely discussed. The authors have investigated the PCM paraffin wax used in highly conductive material like metal foam and ceramic nanoparticles, in order to enhance the heat transfer inside the system. They demonstrated that foam improves significantly the thermal performance of the system in comparison with the nanoparticles, due to the effect of the melting time reduction [9].

In our present research, a methodology, which can be used to assess thermo-physical and energy performance of advanced integrated active façade systems, is provided. The proposed method is based on CFD transient simulations with a multi-physical approach and allows for evaluation of relevant thermo-physical parameters and energy performances of the advanced façade systems with renewable energy 
integrated uses in Mediterranean localizations.

Starting from a recent and wide analysis of recent literature works on this matter in [11], we propose a numerical method that takes into account the basic heat and mass transfer resulting from combined buoyancy effects of temperature and integrated effects due to phase changes.

The numerical solutions provided in our method, for buoyancy/forced driven flows and temperature fields take into account the basic setting of the fluid flow dynamics into open vertical channels and the connected heat and mass transfer referring to the method proposed in [12].

Our method can also be an important predictive simulation tool for establishing the energy design of the AAFs to attain effectiveness, energy sustainability and thermal comfort.

\section{MODELLING}

Different basic typologies of advanced integrated and semiopaque active façades were investigated by fluid-dynamic and thermal analysis developed by CFD transient simulations. Two-dimensional models were built up for two different configurations with respect to corresponding different layers of the building envelope. The solid geometry used for numerical simulations is shown in Figures.1-2. The longitudinal sections are provided together with an enlargement of the top portion.

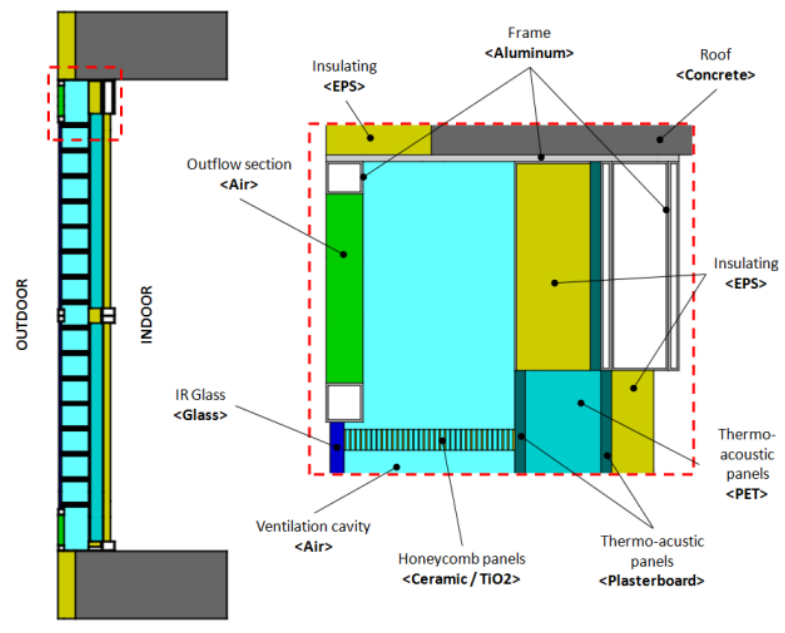

Figure 1. Geometry of system $<\mathrm{AF} 1>$

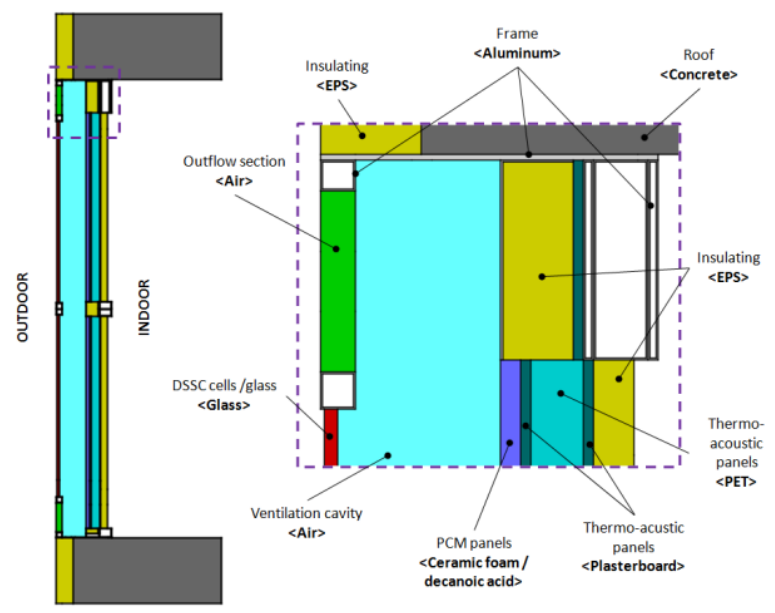

Figure 2. Geometry of system $<$ AF2 $>$
The first façade configuration, called $<\mathrm{AF} 1>$, is composed of a ventilated cavity bounded by an IR glass layer from outdoors and a multilayer wall from indoors.

The air cavity has inlet and outlet sections connected to the external environment, respectively located at the bottom and top. In the air cavity, sixteen honeycomb ceramic panels filled by $\mathrm{TiO}_{2}$ for internal air cleaning and purification are arranged horizontally. The multi-layer wall is composed of a sandwich thermo-acoustic panel (plasterboard and PET) and an insulating EPS panel. The EPS is also used to insulate the concrete at the floor/roof levels and some portions of the aluminum frame of the whole system.

The second façade scheme, called $<\mathrm{AF} 2\rangle$, is similar to $<$ AF1 $>$. The main differences between the above components consist of use of external glass integrated by Dye Sensitized Solar Cells (DSSC) on the external side of the ventilated air cavity and panels made of a Phase Change Material (PCM) embedded in a ceramic foam on the inner side. The $<$ AF2 $>$ system does not include honeycomb panels. In order to assess the PCM thermal buffer and its damping effects due to external climatic cyclic stress, the $<\mathrm{AF} 2>$ system was also simulated without PCM panels. In the latter, the air cavity width was considered higher, including the thickness used for arranging PCM panels. This façade configuration was called $<$ AF3 $>$.

Thermo-physical properties of construction materials used for $<\mathrm{AF} 1>$ and $<\mathrm{AF} 2>$ were obtained by a comparative search of the most significant experimental and testing contributions on this subject, but also of recent commercial technical documentation. They are provided in Table 1.

In particular, literature results of practical tests and assessments of PCM-incorporated building elements widely performed experimentally $[5,7,8,13,14,15]$ were used for dynamic simulations. Thermo-physical properties of PCM panels, given in Table 1, refer to all the values averaged on the experimental evidence provided by recent literature $[14,15]$, evaluated for a finite product made of decanoic acid embedded in a ceramic foam and contained in a plastic envelope. Referring to the PCM studied, the temperature of liquid-solid transition was assumed to be $\mathrm{Tm}=34^{\circ} \mathrm{C}$, with the phase change enthalpy of $\mathrm{L}=153.2 \mathrm{~kJ} / \mathrm{kg}$.

Thermal conductivity values both for liquid (L) and solid (S) state are shown in the same Table 1. Moreover, a solar factor (SF) of 0.67 and a thermal emissivity of 0.84 were chosen for the Infrared Reflective (IR) glass generally used for this application.

Natural convection turbulent flow inside the air cavity of the ventilated façade was solved by considering the Reynolds Averaged Navier-Stokes (RANS) and energy equations under the assumptions of Newtonian fluid and uncompressible flow.

Air density was considered as a temperature dependent variable by means of the ideal gas law. A closure scheme based on a two equation $(\mathrm{k}-\varepsilon)$ turbulence method was adopted for solving the momentum and continuity equations.

At present, the literature here is limited and there are few applied studies on detailed simulation techniques of PCMs for building applications. Fundamental heat and mass exchange governing equations, characterized by non-linear phenomena changing over time and space, especially when the PCM is incorporated and/or encapsulated in opaque/transparent systems, have to be considered for transient numerical simulation assessment.

Starting from some existing fundamental studies on proper PCM transient simulation [12,16], our proposed numerical modelling, using a multi-physics approach, identifies the basic 
problem formulation and parameters required. These parameters include the geometry and discretization of the simulated PCM-incorporated building system, the physics of the system embracing thermo-physical properties, heat transfer and phase change processes and all the basic boundary conditions that were used for transient simulations.

Commercial software that combined the Finite Element Method (FEM) CFD with a multi-physical approach, was used to solve fluid-dynamic and thermal transient simulations.

Continuous equations were discretized by the FEM on nonstructured and non-uniform computational meshes made of triangular Lagrange elements of the second order characterized by 1,570,000 DOF (Figure 3).

Influence of spatial discretization was preliminary checked, in order to assure mesh-independent results. Time-marching was performed by adopting an Implicit Differential-Algebraic (IDA) solver, based on variable-order and variable-step-size Backward Differentiation Formulas (BDF). Due to an implicit time-marching scheme, a nonlinear system of equations was solved at each time step, by applying a modified Newton algorithm. Algebraic systems of equations coming from differential operator discretization were solved by a multifrontal package, i.e. a direct solver particularly efficient for computing unsymmetrical sparse matrixes by an LU decomposition technique.

All the analyses were carried out in transient conditions applying the same boundary thermal constraints to each numerical model used for $<\mathrm{AF} 1>$ and $\langle\mathrm{AF} 2>$, respectively with and without the PCM layer. They correspond to real external climatic conditions concerning the worst and representative day of the summer conditions for a Mediterranean climate (Florence, Italy), the one with maximum values of the air temperature and solar radiation on a vertical south-exposed surface (16 July), that was processed applying the method suggested in [17]. This choice is due to the precautionary conditions imposed for the analyses.

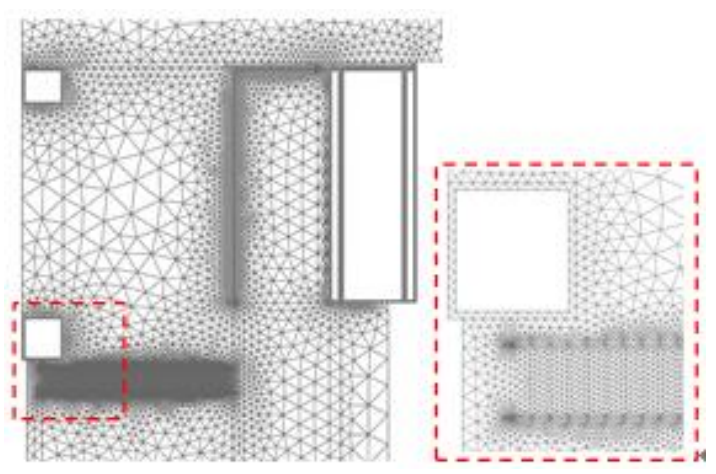

Figure 3. Computational mesh

A stabilized periodic regime was achieved by postprocessing the results by consecutively applying the same thermal constraints for several days of simulations before the above defined "typical day" studied, in order to obtain velocity and temperature fields not dependent on the initial numerical conditions.

The other boundary conditions can be summarized as follows. Convective and surface-to-ambient radiative heat exchange conditions were applied to the external surfaces of the façade, using a heat transfer coefficient $h \_$ext $=23 \mathrm{~W} /\left(\mathrm{m}^{2}\right.$ $\mathrm{K})$ and a thermal emissivity $\varepsilon$ equal to 0.84 .

Convective heat transfer was also assumed for the inner surface of the system, assuming a controlled constant indoor temperature of $\mathrm{T}$ in $=24^{\circ} \mathrm{C}$ and an internal heat transfer coefficient of $h \_$int $=7.7 \mathrm{~W} /\left(\mathrm{m}^{2} \mathrm{~K}\right)$. The above heat transfer coefficients used, were evaluated by referring to $[18,19]$.

The external air flow enters the cavity under variable external conditions over time at the open boundaries of the cavity inner section (inlet grid of the ventilated facade).

Insulation conditions were assumed at all the roof/floor boundaries.

Table 1. Thermo-physical properties of materials

\begin{tabular}{cccc}
\hline Material & Density & $\begin{array}{c}\text { Thermal } \\
\text { conductivity }\end{array}$ & $\begin{array}{c}\text { Specific heat } \\
\text { at constant } \\
\text { pressure }\end{array}$ \\
\hline EPS & {$\left[\mathrm{kg} \mathrm{m}^{-3}\right]$} & {$\left[\mathrm{W} \mathrm{m}^{-1} \mathrm{~K}^{-1}\right]$} & {$\left[\mathrm{J} \mathrm{kg}^{-1} \mathrm{~K}^{-1}\right]$} \\
\hline Concrete & 2200 & 0.03 & 1700 \\
Ceramic/TO 2 & 2100 & 1.8 & 880 \\
PET & 1380 & 1.63 & 1016 \\
Plasterboard & 1900 & 0.28 & 1050 \\
Aluminium & 2800 & 0.20 & 840 \\
Air & $\mathrm{p} \mathrm{R}^{-1} \mathrm{~T}^{-1}$ & 0.026 & 900 \\
Ceramic & 1179 & $0.789(\mathrm{~S}) \div 0.627^{(\mathrm{L})}$ & 1010 \\
foam/Decanoic & & & \\
acid & & 0.937 & 840 \\
IR Glass/ & 2410 & & \\
DSCC Glass & & &
\end{tabular}

\section{RESULTS AND DISCUSSION}

In this section air velocity and temperature fields obtained as results of the governing equation integration are provided and discussed.

The air velocity fields due to natural convection computed at $12.00 \mathrm{hrs}$ are provided in Figure 4 for the $<\mathrm{AF} 1>,<\mathrm{AF} 2>$ and $<$ AF3 $>$ systems. The horizontal honeycomb panels of $<$ AF1 $>$ obstructs the thermal driven airflow inside the ventilation cavity (Figure 5), therefore the velocity magnitude is rather lower than those of $<\mathrm{AF} 2>$ and $<\mathrm{AF} 3>$.
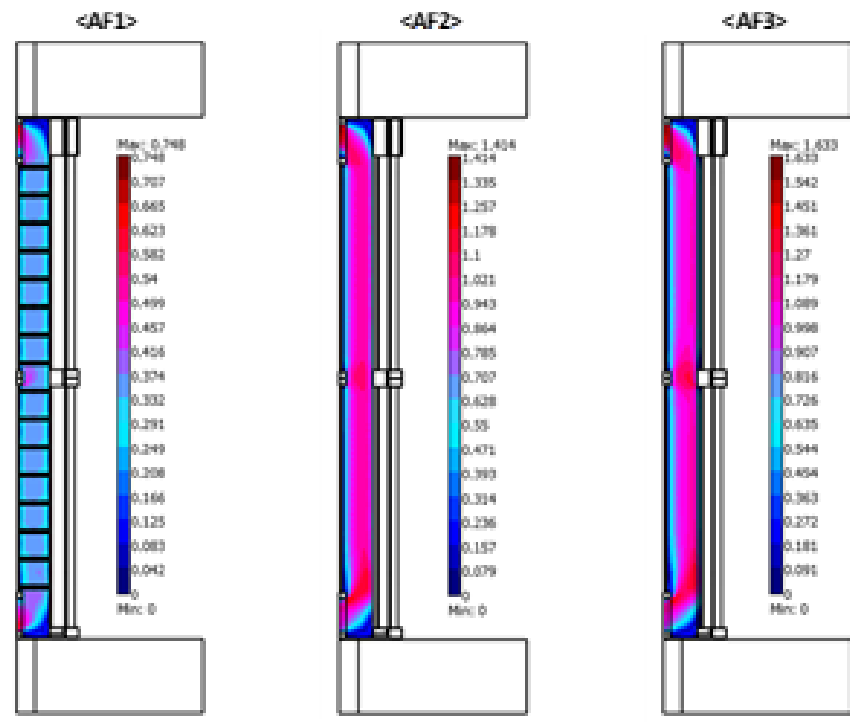

Figure 4. Velocity field $(\mathrm{m} / \mathrm{s})$ at $12.00 \mathrm{hrs}$ for studied systems 


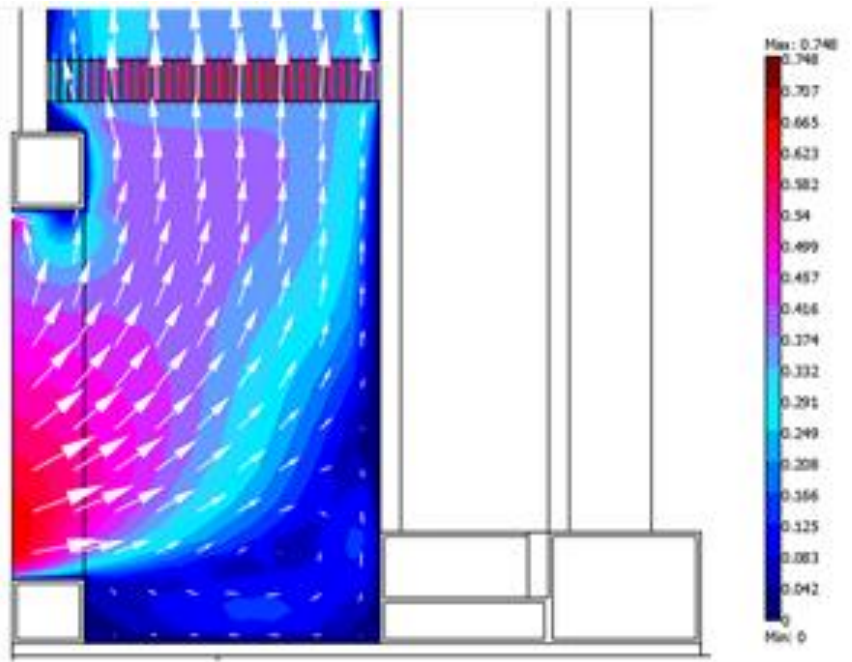

Figure 5. Enlargement of velocity field $(\mathrm{m} / \mathrm{s})$ and velocity vectors at $12.00 \mathrm{hrs}$ for $<\mathrm{AF} 1>$ system

It is important to notice that the colour scale in each plot, given in Figure 4, is adapted to each system, in order to enlarge the air velocity field representation for each one.

The airflow into $<\mathrm{AF} 2>$ and $<\mathrm{AF} 3>$ is very similar, because inside the $<\mathrm{AF} 3>$ system it is more intense, due to the increased width of the ventilation channel with respect to the $<$ AF2 $>$ system.

Figures 6-9 provide the temperature maps evaluated for the $<\mathrm{AF} 1>,<\mathrm{AF} 2>$ and $<\mathrm{AF} 3>$ systems, respectively at $6.00 \mathrm{hrs}$, $12.00 \mathrm{hrs}, 18.00 \mathrm{hrs}$ and $24.00 \mathrm{hrs}$.

In each of these Figures, the colour scale is equal for the three system configurations, being different from one Figure to another for the same reason previously explained.

Thermal map comparison suggests basic considerations, as follows. Due to the low airflow velocity in the ventilation cavity, the air temperature inside $<\mathrm{AF} 1>$ is higher than inside $<\mathrm{AF} 2>$ and $<\mathrm{AF} 3>$, especially in the upper portion of the cavity.

This determines an important vertical thermal gradient in the ventilation cavity of $\angle \mathrm{AF} 1>$ that is transmitted to the layers behind, closer to the indoor environment.
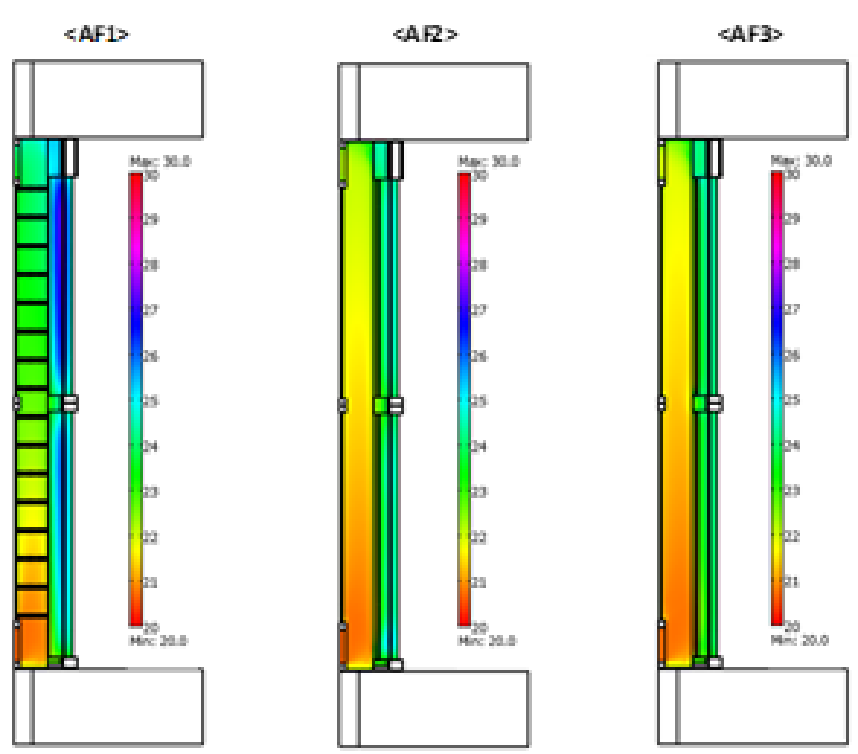

Figure 6. Temperature map at $6.00 \mathrm{hrs}$ for studied systems
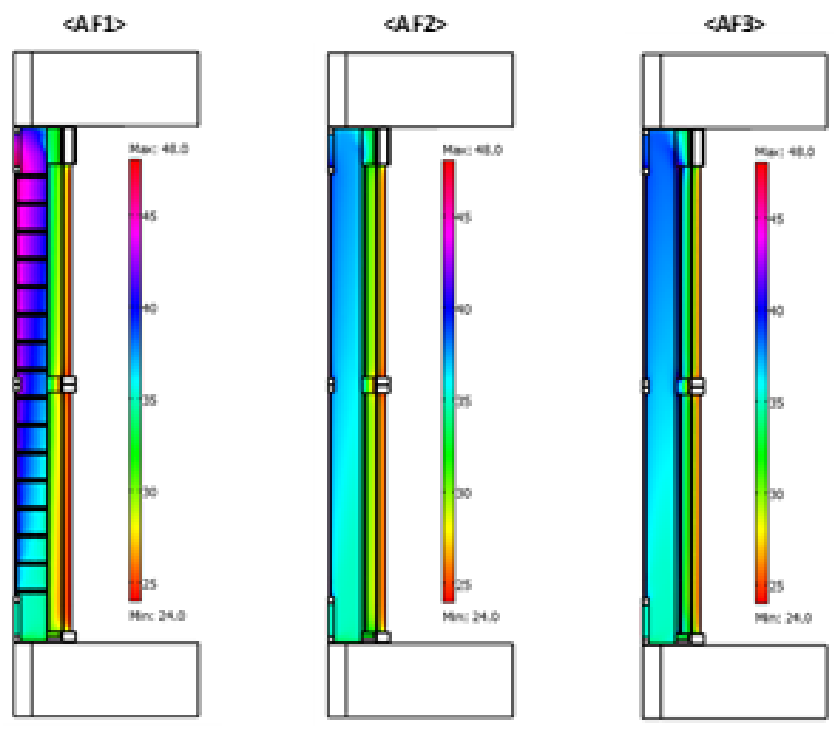

Figure 7. Temperature map at $12.00 \mathrm{hrs}$ for studied systems
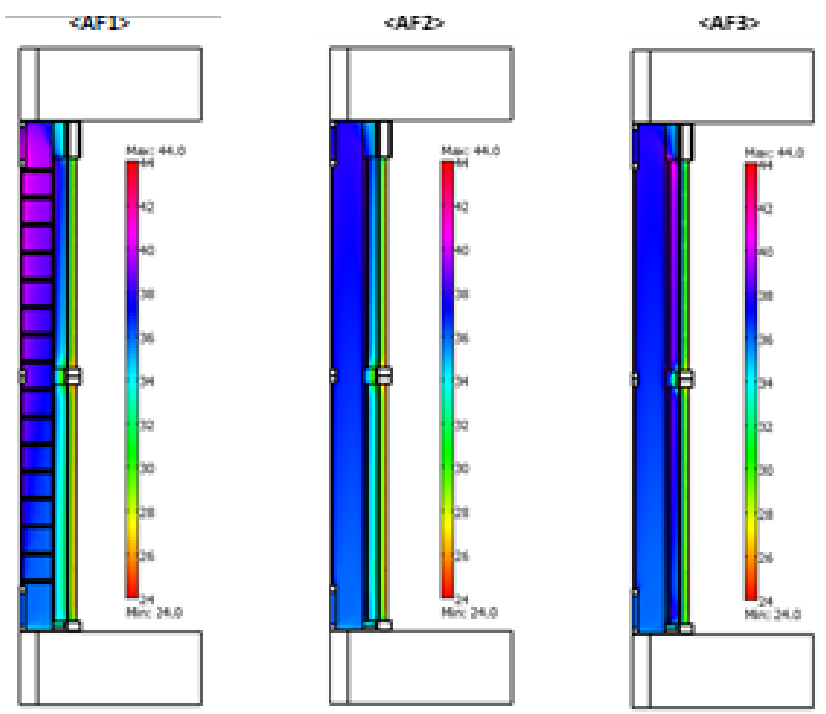

Figure 8. Temperature map at $18.00 \mathrm{hrs}$ for studied systems
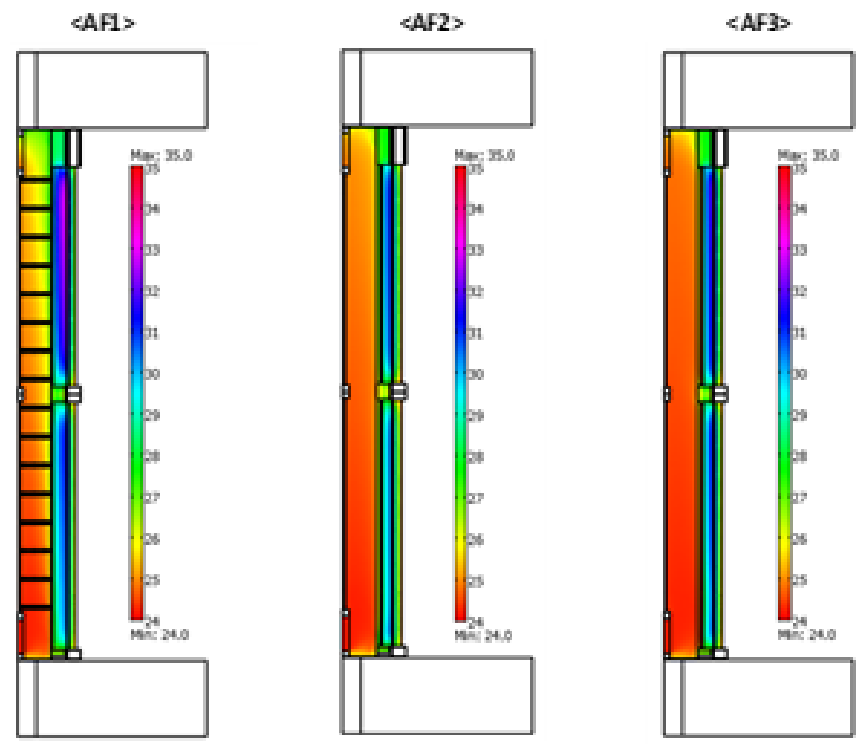

Figure 9. Temperature map at $24.00 \mathrm{hrs}$ for studied systems 
Thermal buffer and damping effect induced by the PCM panel in $<\mathrm{AF} 2>$ is clearly evident with respect to the $<\mathrm{AF} 3>$ configuration, especially in the bottom portion of the system corresponding to the inlet region of the airflow at outside thermal conditions. At $6.00 \mathrm{hrs}$ (Figure 5) temperature values in correspondence to the PCM panel are higher than in $<\mathrm{AF} 2>$ and, at the same time, slightly higher in value with respect to $<$ AF3 $>$ because of the energy buffered during the previous day. Otherwise, at $12.00 \mathrm{hrs}$ (Figure 6) and $18.00 \mathrm{hrs}$ (Fig. 7) the PCM panel allows the maintenance of the temperature lower than the thermal level occurring in $<\mathrm{AF} 3\rangle$.

At 18.00 hrs the PCM layer seems to "lock" the temperature at $34^{\circ} \mathrm{C}$ which corresponds to the solid/liquid phase change of the constituting material used for simulations. On the other hand, at $24.00 \mathrm{hrs}$ (Figure 8) the heat buffered by PCM during the hot portion of the day still allows a higher temperature with respect to that evaluated for $\langle\mathrm{AF} 3>$.

In the bottom portion of the PCM panel inside of the $<\mathrm{AF} 2>$, temperature distribution at $24.00 \mathrm{hrs}$ (Figure 8) highlights the incoming air "impact" on the PCM panel solid interface and then the local increase of heat transfer. This fact is evident when considering the colour variation along the vertical direction given in Figure $9(<\mathrm{AF} 2>$ system $)$ and the velocity field provided in Figure 4 ( $<\mathrm{AF} 2>$ system).

Taking into account the thermal flux transferred to the indoor environment, Figure 10 shows the incident thermal flux to the building envelope, computed by considering the airsolar temperature, fixed indoor air temperature and stationary thermal transmittance of the façade (being about $0.5 \mathrm{~W} /\left(\mathrm{m}^{2} \mathrm{~K}\right)$ for all the three configurations). In the same Figure three curves corresponding to the thermal flux transferred to the indoor environment, evaluated by processing simulation results obtained for $\langle\mathrm{AF} 1>,<\mathrm{AF} 2>$ and $<\mathrm{AF} 3>$, are plotted. Thermal damping and peak-to-peak offset can be clearly appreciated for all the configurations.

Periodic thermal transmittance computed for the system corresponds to $0.229,0.226$ and 0.307 for $<\mathrm{AF} 1>,<\mathrm{AF} 2>$ and $<\mathrm{AF} 3>$, respectively. A considerable gap is found between $<\mathrm{AF} 3>$ and the couple $<\mathrm{AF} 1>$ and $<\mathrm{AF} 2>$.

The presence of the PCM panel in $<\mathrm{AF} 2>$ and the thermal mass of the ceramic honeycomb panels in $\angle \mathrm{AF} 1>$ is very likely to explain the better performance detected with respect to component $<\mathrm{AF} 2>$.

Influence of the PCM panel on thermo-physical performances of the system is strong as Figure 11 shows, where the time series of temperature computed in a point $(\mathrm{x}=0.19 ; \mathrm{y}=2)$ inside the PCM panel are given for $<\mathrm{AF} 2>$. Temperature evolution of the corresponding geometrical point for $<$ AF3 $>$ laying in the air cavity space, is also plotted (Figure 11).

A plateau zone is remarkable for the $<\mathrm{AF} 2\rangle$ curve, corresponding to the solid to liquid phase change during the day. This zone corresponds to timing of intense solar radiation (from $10.00 \mathrm{hrs}$ to $14.00 \mathrm{hrs}$ ) and a temperature close to the solid to liquid phase change.

A fraction of heat received by the ventilated façade from the external climatic thermal load does not contribute to increasing temperature, as it is exchanged latently.

Moreover, referring to recent research on this subject [20] some performance indices, i.e. efficiency of pre-heating (Eq.1), thermal buffer (Eq.2) and dynamic insulation (Eq.3), were also calculated, as following:

$$
\begin{aligned}
& \eta_{P H}=\frac{\left(T_{\text {out }}-T_{\text {inlet }}\right)}{\left(T_{\text {ext }}-T_{\text {in }}\right)} \\
& \eta_{T B}=\frac{\left(T_{\text {ext }}-T_{\text {cav }}\right)}{\left(T_{\text {ext }}-T_{\text {in }}\right)} \\
& \varepsilon=\frac{\dot{Q_{\text {vent }}}}{\dot{Q_{\text {trans }}}}
\end{aligned}
$$

where $T_{\text {out }}$ is the temperature of outflowing air form the cavity, $\mathrm{T}_{\text {inlet }}$ is the inlet air temperature to the cavity, $\mathrm{T}_{\mathrm{ext}}$ is the external air temperature, $T_{\text {in }}$ is the indoor air temperature and $T_{\text {cav }}$ is the average air temperature in the cavity. $Q_{\text {vent }}$ represents the total heat removed from the air cavity by means of ventilation $\left(\mathrm{W} / \mathrm{m}^{2}\right)$ and $\mathrm{Q}_{\text {trans }}$ is the total heat flux transmitted through the façade $\left(\mathrm{W} / \mathrm{m}^{2}\right)$. The thermal buffer efficiency, pre-heating efficiency and the correspondent dynamic insulation efficiency are better for $<$ S2 $>$ configuration due to the PCM presence. The $\eta_{\text {Tв }}$ mainly depends on the difference between the external air temperature and the mean air temperature in the cavity, so that its value is lower when better façade performances are achieved. As a matter of fact, the thermal buffer efficiency of the three building façade systems is almost constant for all the central hours of the day (values in the range $-0.3 \div-0.1)$ with the higher values of the external air temperature and incident solar radiation, but with the best results for the $<$ S2 $>$ configuration.

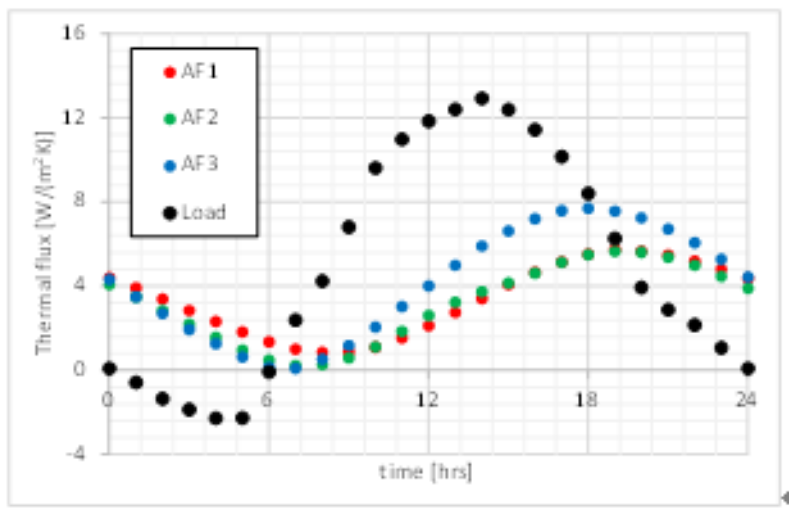

Figure 10. Analytical incident thermal flux (black symbols) and transmitted thermal flux by $<\mathrm{AF} 1>$ (red symbols), $<\mathrm{AF} 2>$ (green symbols) and $<\mathrm{AF} 3>$ (blue symbols)

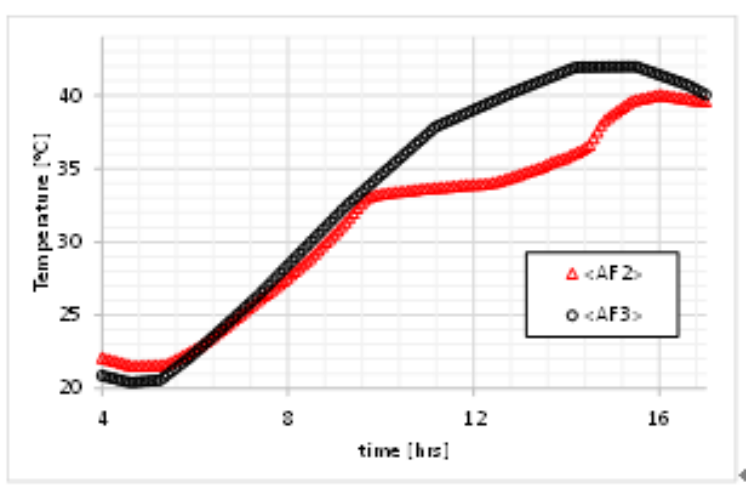

Figure 11. Time evolution of temperature in a point lying in the $\mathrm{PCM}$ panel of $<\mathrm{AF} 2>$ and in the air cavity of $<\mathrm{AF} 3>$ 


\section{CONCLUSIONS}

The proposed method can be a useful tool for quantifying the energy performance of different AAIFs and an overall initial quantification of the potential energy saving achievable with a dynamic and adaptive façade system.

Results demonstrated that a shorter reaction time of the façade, due to the PCM introduction, could result in better thermal performance. Transient simulation demonstrated that PCM use provides a fundamental thermal buffer effect strictly connected to the cyclic climatic stress. CFD simulation based on a multi-physics approach has proved to be an accurate technique for solving some details in AAIF design developing coupled numerical models.

Transient simulation results also demonstrated that the PCM inside the air cavity increases the heat storage capacity and then thermal inertia of the system, making its use suitable for a Mediterranean climate.

Moreover, the ventilated façade can be used as cold storage during summer periods, using the night cooling effect only when the PCM has been fully solidified during the night, and the use of ceramic elements guarantees a high thermal capacity over time. Our proposed modelling approach can be applied to possible retrofit design on existing buildings, aiming at an increase in their energy performance.

Furthermore, the climate in the Mediterranean region has a set of challenges for all AAIF technologies, that make them energy sustainable and effective solutions, especially in summer, when they operate as an adaptive dynamic building envelope.

\section{ACKNOWLEDGMENT}

The present research study falls within a funded project. The authors express their gratitude to the Tuscany Region for the financial support from the PAR-FAS 2007-2013, SELFIE Project.

\section{REFERENCES}

[1] Szakály F., Hortobágyi Z., Bagi K. (2016). Discrete element analysis of the shear resistance of planar walls with different bond patterns, Open Constr. Build. Technol. J., Vol. 10, No. Suppl 2, pp. 220-232. DOI: 10.2174/1874836801610010220

[2] Elarga H., De Carli M., Zarrella A., Abo E.M., Alvarez C. (2015). Assessment of active double skin facade integrated with PV cell, ASHRAE Winter Conference January 2015, Chicago, Volume III.

[3] Corgnati S.P., Perino M., Serra V. (2007). Experimental assessment of the performance of an active transparent façade during actual operating conditions, Sol. Energy, Vol. 81, pp. 993-1013. DOI: 10.1016/j.solener.2006.12.004

[4] ETHICS, Energy and Thermal improvements for Construction in Steel (2008). RFSR-CT-2008-00038.

[5] De Gracia A., Cabeza L.F. (2015). Phase change materials and thermal energy storage for buildings, Energy Build, Vol. 103, pp. 414-419. DOI: $\underline{10.1016 / j . e n b u i l d .2015 .06 .007}$

[6] Liu P.F., Lin Y.P., Tzeng C.T., Lai C.M. (2016). Heat transfer and energy performance of a PVA wall tile containing macro-encapsulated PCM, Energies, Vol. 9, No. 8, pp. 652-2016. DOI: 10.3390/en9080652

[7] Tittelein P., Gibout S., Franquet E., Johannes K., Zalewski L., Kuznik F., Dumas J.P., Lassue S., Bédécarrats J.P., David D. (2015). Simulation of the thermal and energy behaviour of a composite material containing encapsulated-PCM: Influence of the thermodynamical modelling, Appl. Energy, Vol. 140, pp. 269-274. DOI: 10.1016/j.apenergy.2014.11.055

[8] Hawlader M.N.A., Uddin M.S., Zhu H.J. (2002). Encapsulated phase change materials for thermal energy storage: Experiments and simulation, International Journal of Energy Research, Vol. 26, No. 2, pp. 159-171. DOI: $10.1002 /$ er.773

[9] Buonomo B., Ercole D., Manca O., Nardini S. (2016). Thermal behaviors of latent thermal energy storage system with PCM and aluminum foam, Int. J. Heat and Tech., Vol. 34, Sp. 2, pp. 359-364. DOI: 10.18280/ijht.34s224

[10] Casano G., Piva S. (2015). Parametric analysis of a PCM energy storage system, Int. J. Heat Tech., Vol. 33, No. 4, pp. 61-68. DOI: 10.18280/ijht.330408

[11] Lai C.M., Hokoi S.C. (2015). Solar façades: A review, Build. Environ., Vol. 91, pp. 152-165. DOI: 10.1016/j.buildenv.2015.01.007

[12] Cammarata G., Monaco L., Cammarata L., Petrone G. (2013). A numerical procedure for PCM thermal storage design in Solar plants, Int. J. Heat Tech., Vol. 31, No. 2, pp. 105-110. DOI: 10.18280/ijht.310214

[13] Hasse C., Grenet M., Bontemps A., Sallée L.H. (2011). Realization, test and modelling of honeycomb wallboards containing a phase change material, Energy Build., Vol. 43, No. 1. DOI: $\underline{10.1016 / j . e n b u i l d .2010 .09 .017}$

[14] Paris Fokaides A., Kylili A., Kalogirou S.A. (2015). Phase change materials (PCMs) integrated into transparent building elements: A review, Int. J. Mater. Renewable Sustainable Energy, pp. 4-6. DOI: 10.1007/s40243-015-0047-8

[15] Brandl D., Mach T., Kaltenecker P., Sterrer R., Neururer C., Treberspurg M., Hochenauer C. (2015). CFD assessment of a solar honeycomb (SHC) façade element with integrated PV cells, Sol. Energy, Vol. 118, pp.155-174. DOI: $\underline{10.1016 / j . s o l e n e r .2015 .03 .053}$

[16] Bonacina C., Comini G., Fasano A., Primicerio M. (1973). Numerical solution of phase change problems, Int. J. Heat Mass Transfer, Vol. 16, pp. 1825-1832. DOI: $10.1016 / 0017-9310(73) 90202-0$

[17] Hygrothermal performance of buildings - Calculation and presentation of climatic data - Part 4: Hourly data for assessing the annual energy use for heating and cooling (2005). ISO 15927-4.

[18] Thermal Performance of Buildings. Transmission and Ventilation Heat Transfer Coefficients. Calculation Method (2007). EN ISO 13789:2007.

[19] Building Components and Building Elements. Thermal Resistance and Thermal Transmittance. Calculation Method (2007). EN ISO 6946:2007.

[20] Favoino F., Goia F., Perino M., Serra V. (2016). Experimental analysis of the energy performance of an ACTive, RESponsive and Solar (ACTRESS) façade module, Sol. Energy, Vol. 133, pp. 226-248. DOI: $\underline{10.1016 / j . s o l e n e r .2016 .03 .044}$ 